\title{
Predictive diagnosis of peripheral neuropathy and foot deformity in diabetics using plantar thermographic imaging
}

\author{
Rodríguez-Alonso D*, Cabrejo-Paredes $\mathrm{J}^{\star \star}$ and Benites-Castillo $\mathrm{S}^{\star \star *}$ \\ *“Innovaciones pie diabetico” medical Centre, Trujillo, Peru, ortocentro30@gmail.com \\ ${ }^{* *}$ Postgraduate research Unit, National University of Trujillo, Trujillo, Peru, jcabrejop@gmail.com \\ ${ }^{\star * \star}$ Research Institute, University of Cesar Vallejo, Trujillo, Peru ,santiagob@ucv.edu.pel
}

\begin{abstract}
The aim was to apply a predictive diagnostic model(PDM) using thermographic point measurements(TPM) on sole in diabetics with and without complications such as peripheral neuropathy (PN), peripheral arterial disease(PAD) and foot deformity(FD). This images study was a cross-sectional design of diabetics with and without complications respect 9 TPM on sole using a FLIR E60 camera. 288 thermographic images were analysed by binary logistic regression model being significant in hallux $\left(p=0.04\right.$, OR:1.58), $1^{\text {st }}$ metatarsus $(p=0.03, O R: 0.49), 3^{\text {rd }}$ metatarsus $(p=0.02, O R: 2.26)$ for FD and $3^{\text {rd }}$ metatarsus ( $p=0.02$, OR:2.47) for PN . In conclusion ,PDM were for FD and PN.
\end{abstract}

\section{Introduction}

The diabetic foot is a syndrome clinically characterized in chronic ulcers preceded by factors such as peripheral neuropathy, peripheral arterial disease and foot deformity [1]. The identification of the above factors is a priority for primary health care and ulcer prevention in diabetics [2].

Peripheral neuropathy (PN) is anatomical and physiological alteration of distal somatic, sensory and autonomic peripheral nerves [3]. Peripheral arterial disease (PAD) is anatomical and physiological macroscopic alteration of distal arteries of the lower limbs caused by obstruction of their lumen or thickening [4]. Foot deformity (PD) is anatomical and biomechanical alteration of skeletal muscle of the foot, and its common presentation are corns, hallux valgus, claw or hammertoes, pes cavus or flatfoot [4].

Infrared thermography is a diagnostic imaging methodology that uses infrared wave emitted by skin that is then transformed into a coloured image to finally be analysed [6]. The use of thermography in the diabetic foot is a feasible, non-invasive, accurate, accessible, promising and innovative diagnostic support methodology [7,8].Analysis methodology of thermographic imaging can be performed by computational processes of comparison of symmetry, point-sector measurement or combination [9].

Infrared thermography as an innovative diagnostic support methodology, priority of predicting peripheral complications pathologies and prevention as a primary healthcare intervention avoiding ulcers and amputations were arguments to apply a predictive model of thermographic measurements of sole in diabetic patients with peripheral foot complications such as peripheral neuropathy, peripheral arterial disease and deformity.

\section{Material and methods}

This clinical study and biomedical imaging had a cross-sectional design with multiple observational groups of diabetics with peripheral foot complications compared to a control group. Independent variables were thermographic measurements of hallux plantar zone $(\mathrm{P} 1), 1^{\text {st }}$ metatarsal plantar zone $(\mathrm{P} 2), 3^{\text {rd }}$ metatarsus plantar zone (P3), $5^{\text {th }}$ metatarsus plantar zone (P4), heel plantar zone (P5), $2^{\text {nd }}$ to $5^{\text {th }}$ toe plantar zone (P6 to P9 respectively). Dependent variables were the clinical status of the diabetic classified in group 1 to 4 . Sample population was 304 diabetic patients identified with peripheral neuropathy(PN), peripheral arterial disease(PAD) and foot deformity(FD) according to International Working Group on Diabetic Foot (IWGDF) in primary healthcare study that was performed thermographic imaging of sole, then these were selected randomly simple and with a minimum of 30 for each group. Four groups had following inclusion criteria:

- Group 1(control): Diabetics without foot deformity, peripheral neuropathy or peripheral arterial disease,

- Group 2: Diabetics with foot deformity characterized by having only skeletal muscle alterations at least three.

- Group 3: Diabetics with peripheral neuropathy characterized by alterations in tactile or vibratory sensitivity and /or neuropathic pain.

- $\quad$ Group 4: Diabetics with peripheral arterial disease characterized by arm-ankle index in less than 0.9.

The analysis unit of sample was feet in each patient evaluated. Biomedical images were acquired by thermography after their clinical evaluation by photography of soles in dorsal decubitus position on a clinical stretcher conditioned to approach soles using a FLIR E60 camera at a distance of 80 to $100 \mathrm{~cm}$ perpendicular to soles( see figure 1) under specific adaptation conditions 15 minutes prior to process according to American Academy Thermology[10]. Images were then analysed using FLIR TOOL software by expert physician considering thermographic measurements at $\mathrm{P} 1$ to $\mathrm{P} 9$ at ${ }^{\circ} \mathrm{C}$. The data collection was done with a card validated by experts in diabetic foot and thermography. All patients accepted informed 
consent, confidentiality of each patient's data was performed, and an ethics committee permission was obtained. The statistics have consisted in descriptive and inferential analysis by binary regression model.

\section{Results}

This study evaluated 144 patients which was classified as follows: 41 for group 1, 35 for group 2, 36 for group 3 , 32 for group 4 and their general characteristics are indicated in table 1. The data analysed in total were 288 thermographic images corresponding to each sole in each patient for each group with measurements from P1 to P9(see figure 2) and these data did not meet linearity, normality, and homogeneity criteria for each group. Data were analysed by ANOVA one factor considering thermographic measurements from P1 to P9 in each groups and Games-Howell test was used. Significant results were given only for group 2 in points P2, P4, P5, P8, P9 and for group 3 in points P1 to P9. Group 4 was not significant in all points. Then, this study proposed a binary logistic regression model with multiple independent variables for 2 and 3 groups considering all points P1 to P9 due to interaction. Analysis of binary logistic regression for group 2 with respect to control found only significance in the measurements from P1 to P3. Predictive model for this case found that for every $1^{\circ} \mathrm{C}$ increased temperature in $\mathrm{P} 1$ there will increase in $58 \%$ probability that a diabetic present deformity with respect to control, for every $2{ }^{\circ} \mathrm{C}$ increased temperature in P3 there will increase in $26 \%$ probability that a diabetic present deformity with respect to control and for every $1{ }^{\circ} \mathrm{C}$ temperature in P2 there will decreases in $4.9 \%$ probability that a diabetic present deformity respect to control. Analysis of binary logistic regression for group 3 with respect to control found that for every $2{ }^{\circ} \mathrm{C}$ increased temperature in P3 there will increase in $47 \%$ probability that a diabetic presents peripheral neuropathy more with respect to control, for more details see Table 3.

Table 1. General characteristics of 144 diabetics type 2 diagnosed with peripheral foot complications

\begin{tabular}{|c|c|c|c|c|c|c|c|c|c|}
\hline \multirow[t]{2}{*}{ characteristic } & \multirow[t]{2}{*}{ Parameter } & \multicolumn{2}{|c|}{$\operatorname{group} 1^{*}(\mathrm{n}=41)$} & \multicolumn{2}{|c|}{ group $2 \dagger(n=35)$} & \multicolumn{2}{|c|}{ group $3 \ddagger(n=36)$} & \multicolumn{2}{|c|}{ group 4ף $(n=32)$} \\
\hline & & $\mathrm{n}$ & $\%$ & $\mathrm{n}$ & $\%$ & $\mathrm{n}$ & $\%$ & $\mathrm{n}$ & $\%$ \\
\hline demographic & $\begin{array}{l}\text { Gender } \\
\text { feminine } \\
\text { masculine }\end{array}$ & $\begin{array}{l}19 \\
22\end{array}$ & $\begin{array}{l}46,3 \\
53,7\end{array}$ & $\begin{array}{l}20 \\
15\end{array}$ & $\begin{array}{l}57,1 \\
42,9\end{array}$ & $\begin{array}{l}21 \\
15\end{array}$ & $\begin{array}{l}58,3 \\
41,7\end{array}$ & $\begin{array}{l}22 \\
10\end{array}$ & $\begin{array}{l}68,7 \\
31,3\end{array}$ \\
\hline Diabetes & $\begin{array}{l}\text { Diagnostic } \\
\text { Less than } 5 \text { years ago } \\
5 \text { or more years ago } \\
\text { Regular control } \\
\text { Yes } \\
\text { Not } \\
\text { Comorbidity } \\
\text { Yes } \\
\text { Not }\end{array}$ & $\begin{array}{c}14 \\
27 \\
36 \\
4 \\
\\
19 \\
22\end{array}$ & $\begin{array}{l}34,1 \\
65,9 \\
\\
87,7 \\
12,2 \\
46,3 \\
53,7\end{array}$ & $\begin{array}{l}31 \\
4 \\
23 \\
12\end{array}$ & $\begin{array}{r}34,3 \\
65,7 \\
\\
88,6 \\
11,4 \\
65,7 \\
34,3\end{array}$ & $\begin{array}{l}26 \\
10 \\
18 \\
18 \\
\end{array}$ & $\begin{array}{l}33,3 \\
66,7 \\
72,2 \\
27,8 \\
50 \\
50\end{array}$ & $\begin{array}{l}10 \\
22\end{array}$ & $\begin{array}{r}31,3 \\
68,8 \\
\\
71,9 \\
28,1 \\
71,9 \\
28,1\end{array}$ \\
\hline
\end{tabular}

*: without foot deformity or peripheral neuropathy or peripheral arterial disease, $\uparrow:$ with foot deformity, $\ddagger$ : with peripheral neuropathy, ף: with peripheral arterial disease

Table 2. Estimated Parameters of Binary Logistic Regression Model for Predicting Diabetics with deformity

\begin{tabular}{|c|c|c|c|c|c|c|c|}
\hline \multirow[t]{2}{*}{$\alpha: 0.05$} & \multirow[t]{2}{*}{ B } & \multirow{2}{*}{$\begin{array}{l}\text { standard } \\
\text { error }\end{array}$} & \multirow[t]{2}{*}{ Wald } & \multirow[t]{2}{*}{ Sig. } & \multirow{2}{*}{$\begin{array}{l}\text { Odds } \\
\text { ratio }\end{array}$} & \multicolumn{2}{|c|}{$95 \% \mathrm{Cl}$ for $\exp (\mathrm{B})$} \\
\hline & & & & & & Inferior & Superior \\
\hline $\mathrm{P} 1^{*}$ & 0,459 & 0,227 & 4,070 & 0,044 & 1,582 & 1,013 & 2,470 \\
\hline P2† & $-0,712$ & 0,326 & 4,768 & 0,029 & 0,491 & 0,259 & 0,930 \\
\hline P3 & 0,818 & 0,357 & 5,245 & 0,022 & 2,266 & 1,125 & 4,565 \\
\hline Constant & 8,698 & 2,589 & 11,289 & 0,001 & 5990,642 & & \\
\hline
\end{tabular}

*: hallux plantar zone, $\uparrow: 1^{\text {st }}$ metatarsus plantar zone, $\ddagger: 3^{\text {rd }}$ metatarsus plantar zone.

Table 3. Estimated Parameters of Binary Logistic Regression Model for Predicting Diabetics with peripheral neuropathy

\begin{tabular}{|c|c|c|c|c|c|c|c|}
\hline \multirow[t]{2}{*}{$\alpha: 0.05$} & \multirow[t]{2}{*}{ B } & \multirow{2}{*}{$\begin{array}{l}\text { standard } \\
\text { error }\end{array}$} & \multirow[t]{2}{*}{ Wald } & \multirow[t]{2}{*}{ Sig. } & \multirow{2}{*}{$\begin{array}{l}\text { Odds } \\
\text { ratio }\end{array}$} & \multicolumn{2}{|c|}{$95 \% \mathrm{Cl}$ for $\exp (\mathrm{B})$} \\
\hline & & & & & & Inferior & Superior \\
\hline $\mathrm{P}^{*}$ & 0,905 & 0,392 & 5,326 & 0,021 & 2,472 & & \\
\hline constant & 1,574 & 2,425 & 0,421 & 0,516 & 4,825 & 1,146 & 5,331 \\
\hline
\end{tabular}

*: 3rd metatarsus plantar zone 


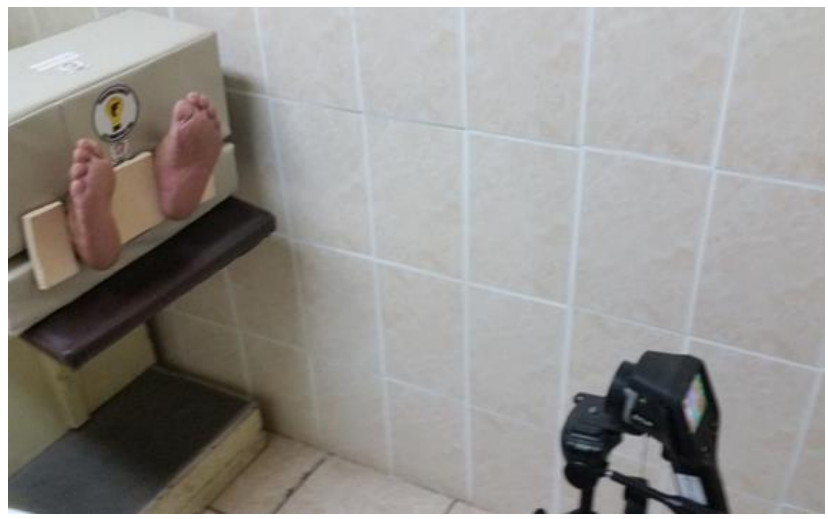

Figure 1. approach of sole by thermographic imaging in 4 diabetics groups

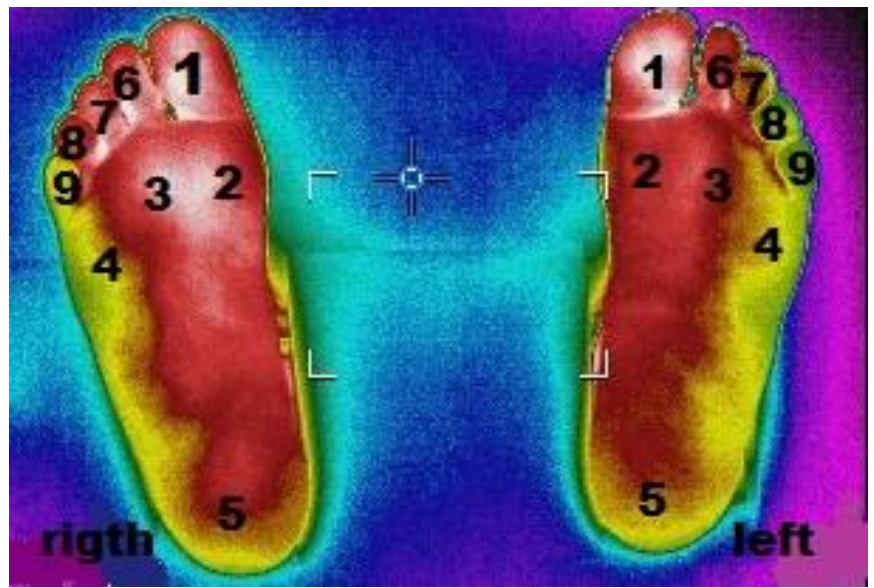

Figure 2. thermographic measurements in 9 points on each sole in 4 diabetic groups

\section{Discussion}

The diagnosis of diabetic peripheral foot complications such as foot deformity(FD), peripheral neuropathy(PN) and peripheral arterial disease(PAD) are very important for ulcerative prevention according to IWGDF guidelines[11]. The methodology mentioned above uses conventional clinical examination in the context of primary healthcare being a dependent operator and limited objectivity[12].The use of infrared thermography as an innovative support to the diagnosis of skeletal muscle, neurological and peripheral arterial pathology in diabetics has been positively evidenced in a narrative review[13].Plantar zone is a very accessible and easy topographic area to approach in anatomical and physiological peripheral skeletal muscle, neurological and arterial structures by thermography[14].

The increase in plantar temperature in group 2 (diabetics with FD) with respect to control was not found in a similar study for comparison. Explanation about increased temperature over skin areas in greatest plantar support of foot is caused by biomechanical stress of gait in deformed foot [15].

The increase in plantar temperatures in group 3 (diabetics with PN) with respect to control was found to be similar to some studies[16-18]. Explanation about increased temperature is due to peripheral neurological dysfunction caused by permanent vasodilatation produced by vasoconstriction deficiency of autonomic motor response[19].

These results do not coincide with some studies[20,21] respect to group 4(diabetics with PAD).Increased temperature of plantar areas of these studies was because including diabetic patients with severe PAD with an index of ankle-arm less than 0.6 , but this study considered only 2 cases with mentioned index in 32 patients in that group. Explanation about increased temperature is similar to neuropathy, but greater time and intensity of vasodilatation is added due to total absence of vasoconstriction $[19,22]$.

The logistic regression model for prediction of diabetics with PD and diabetics with NP in this study used only the measurements of the plantar points. Other factors such as age, ear temperature and body mass index were not considered due to their lower precision and greater subjectivity of diagnostic support. The model mentioned to predict FD in diabetics was significantly influenced by thermographic measurements from P1 to P3 in particular for P1; this means greater plantar support in deformity was presented in medial column of foot and this was explained because plantar support of hallux on the walk [23]. The logistic regression model to predict NP in diabetics in this study was influenced with respect 
to the control significantly in P3. This would be explained because the mentioned zone is located in the innervation of the medial plantar which is the earliest to be affected [24].

This study had identified prediction for PD and NP in diabetics within primary healthcare context that makes it very useful as a prevention intervention; there was only one similar study [25] but with diabetics with unclassified peripheral complications and secondary healthcare. This study considered a diabetic population with stable conditions in medical and metabolic control, minimal concomitant diseases and no ulcers to avoid bias.

In conclusion, this cross-sectional design study with a predictive diagnostic model in type 2 diabetics found that foot deformity was influenced by increases of thermographic measurements in P1 and P3 and reduction in P2, peripheral neuropathy was influenced by increases of thermographic measurements in P3 and peripheral arterial disease was not influenced by any measurement. These predictive models can be used to perform prevention in foot deformity and peripheral neuropathy using thermographic imaging of sole in primary healthcare and thus avoid diabetic ulcers.

\section{REFERENCES}

[1] Ahmad J., Review: the diabetic foot. Diabetes Metab Syndr,Vol.10,pp.48-60, 2016.

[2] Bus SA., Van Netten JJ., Lavery LA., International Working Group on the Diabetic Foot., IWGDF guidance on the prevention of foot ulcers in at-risk patients with diabetes. Diabetes Metab Res Rev,Vol.32, Suppl. 1,pp.1634, 2016.

[3] Volmer-Thole M., Lobmann R,. Neuropathy and Diabetic Foot Syndrome. Int J Mol Sci,Vol.17,pp.1-11,2016.

[4] Mascarenhas JV., Albayati MA., Shearman CP., Jude EB., Peripheral arterial disease. Endocrinol Metab Clin North Am,Vol.43,pp.149-66, 2014.

[5] Allan J., Munro W., Figgins E., Foot deformities within the diabetic foot and their influence on biomechanics: A review of the literature. Prosthet Orthot Int,Vol.40,pp.182-92, 2016.

[6] Brioschi M., Teixeira ML., Silva MT., Colman FM., Medical Thermography Textbook: Principles and Applications, $1^{\text {st }}$ edition ,pp.9-10, Editora e Livrarai Andreoli, Sao Paulo, 2010.

[7] Diakides M., Bronzino JD., Peterson DR., Medical infrared imaging: principles and practices . $1^{\text {st }}$ edition,pp.6898, Taylor and Francis Group, Rio Bacon ,2013.

[8] Sousa P., Felizardo V., Oliveira D., Couto R., et al., A review of thermal methods and technologies for diabetic foot assessment. Expert Rev Med ,vol.12 ,pp. 439-48,2015.

[9] Adam M., Ng EYK., Tan JH., Heng ML., et al., Computer aided diagnosis of diabetic foot using infrared thermography: A review. Comput Biol Med, Vol.91,pp.326-36, 2017.

[10] American Academy of Thermology., Guidelines for neuromusculoskeletal infrared thermography sympathetic skin response (SSR) studies., Pan Am J Med Thermol,Vol.2,pp.35-43,2015.

[11] Schaper N., Van Netten J., Apelqvist J., International Working Group on the Diabetic Foot, Prevention and management of foot problems in diabetes: a Summary guidance for daily practice 2015, based on the IWGDF Guidance Documents, Diabetes Metab Res Rev, Vol.32, pp.7-15, 2016.

[12] Formosa C., Gatt A., Chockalingam N., A critical evaluation of existing diabetic foot screening guidelines. Rev Diabet Stud,Vol. 13,pp.158-86, 2016.

[13] Hernandez-Contreras D., Peregrina-Barreto H., Rangel-Magdaleno J., Gonzalez-Bernal J.. Narrative review: Diabetic foot and infrared thermography. Infrared Physics \& Technology, Vol.78 ,pp.105-17,2016.

[14] Astasio-Picado A., Escamilla Martínez E., Gómez-Martín B., Thermal map of the diabetic foot using infrared thermography. Infrared Physics \& Technology, Vol.93,pp.59-62, 2018.

[15] Yavuz M., Brem RW., Glaros AG., Garrett A., et al., Association between plantar temperatures and triaxial stresses in individuals with diabetes. Diabetes Care,Vol.38,pp.e178-9, 2015.

[16] Chatchawan U., Narkto P., Damri T., Yamauchi J., An exploration of the relationship between foot skin temperature and blood flow in type 2 diabetes mellitus patients: a cross-sectional study. J Phys Ther Sci,Vol. 30,pp. 1359-63, 2018.

[17] Bagavathiappan S.,Philip J.,Jayakumar T., et al.Correlation between plantar foot temperature and diabetic neuropathy: a case study by using an infrared thermal imaging technique. J Diabetes Sci Technol, Vol. 4, pp.1386-92, 2010

[18] Mazilu G., Filos C., Popescu CD., Cutaneous thermographic changes in diabetic polyneuropathy. Rev Med Chir Soc Med Nat lasi, Vol.115,pp.1007-11,2011.

[19] Renero-CF., The thermoregulation of healthy individuals,overweight-obese, and diabetic from the plantar skin thermogram: a clue to predict the diabetic foot. Diabetic Foot \& Ankle,Vol.8,pp.1-8, 2017.

[20] Gatt A., Cassar K., Falzon O., et al., The identification of higher forefoot temperatures associated with peripheral arterial disease in type 2 diabetes mellitus as detected by thermography.Prim Care Diabetes, Vol.12,pp.312-18, 2018.

[21] Sturgeon CD., Cassar K., Falzon O., Thermographic imaging in diabetic patients with critical limb ischemia undergoing endovascular revascularisation. J Angiol Circulat Sys,Vol.1 ,pp.1-8, 2019.

[22] Adiraju RK., Dysautonomia Type 2 diabetes and vasculitis.J Indian Coll Cardiol,Vol.6,pp.70-6, 2016.

[23] Tang UH., Zügner R., Lisovskaja V., Karlsson J., et al., Foot deformities, function in the lower extremities, and plantar pressure in patients with diabetes at high risk to develop foot ulcers. Diabet Foot Ankle,Vol6,pp.1-10, 2015. 
[24] An JY., Park MS., Kim JS., Shon YM., et al., Comparison of diabetic neuropathy symptom score and medial plantar sensory nerve conduction studies in diabetic patients showing normal routine nerve conduction studies. Intern Med,Vol.47,pp.1395-8, 2008.

[25] Gatt A., Falzon O., Cassar K., Ellul C., et al., Establishing differences in thermographic patterns between the various complications in diabetic foot disease. Int J Endocrinol, Vol.12,pp.1-7, 2018. 